\title{
GROWTH PATTERNS AND REGIME CHANGE IN NATIONALLY SHARED ELECTRONIC BANKING NETWORKS: AN ECONOMETRIC ANALYSIS OF CIRRUS AND PLUS
}

\author{
Arun Bansal \\ Yu-Ming Wang \\ Department of Information, Operations, and Management Sciences \\ Leonard N. Stern School of Business, New York University \\ 44 West $4^{\text {th }}$ Street, New York, NY 10012
}




\title{
GROWTH PATTERNS AND REGIME CHANGE
}

\section{IN NATIONALLY SHARED ELECTRONIC BANKING NETWORKS:}

\author{
AN ECONOMETRIC ANALYSIS OF CIRRUS AND PLUS
}

September 15, 1992

\author{
ROBERT J. KAUFFMAN \\ Associate Professor of Information Systems \\ Stern School of Business \\ New York University \\ YU-MING WANG \\ Doctoral Program in Information Systems \\ Stern School of Business \\ New York University
}

An abbreviated version of this paper is forthcoming in Proceedings of the Hawaii International Conference on Systems Science, Maui, Hawaii, January 1993.

\section{ACKNOWLEDGEMENTS}

The authors wish to thank the following people and organizations who have helped to make this research possible: Richard C. Yanak, President, and Richard Symington, Vice President, New England Network Inc.; Joseph S. Pendleton III, Senior Vice President, Electronic Banking, Meridian Bancorp; Joseph Wolfson, President, MAC/MetroTeller; Lucy Rognes, Vice President, and Ron Reed, Senior Vice President, PLUS Systems, Inc.; Linda Snelgrove, CIRRUS Systems, Inc. We benefitted from discussions with James McAndrews, Stephen Felgran, Vijay Gurbaxani and Ed Roche along the way. More recently, Bill Greene, Bruce Weber and Hank Lucas offered useful perspectives about the research approach we selected. Finally, we thank Marybeth Theisen and Ajay Arora for research assistance. Portions of this work were supported by the Center for Research on Information Systems and the U.S.-Japan Business and Economics Research Center, Stern School of Business, New York University, and Nippon Electric Corporation. 
Center for Digital Economy Research Stern School of Business

Working Paper IS-92-32 
IN NATIONALLY SHARED ELECTRONIC BANKING NETWORKS:

AN ECONOMETRIC ANALYSIS OF CIRRUS AND PLUS

\begin{abstract}
Does adoption of shared electronic banking network technology in the financial services industry exhibit S-curve growth patterns as other technologies do? This paper examines this issue in the context of an econometric analysis of the national networks, CIRRUS and PLUS. When the size of the CIRRUS and PLUS networks grew into the range of market saturation, network operators decided in favor of "duality", a move to share their assets, while maintaining separate corporate identities. This research offers empirical evidence that it may be necessary to formulate more sophisticated models to describe the process of adoption and diffusion of an innovation in the presence of market competition.
\end{abstract}


Center for Digital Economy Research

Stern School of Business

Working Paper IS-92-32 


\section{INTRODUCTION}

Shared networks are rapidly becoming a competitive necessity in business, and are likely to have fundamental impacts on transaction costs in a wide variety of industries. Electronic data interchange (EDI), for example, was reported to be used by $75 \%$ of the Fortune 100 and $39 \%$ of the Fortune 500 in January 1988, to perform traditional business communications processes (Canright, 1988). Although EDI deployment is still in its early stages, market researchers have estimated that the market should observe explosive growth of $40 \%$ to $80 \%$ through the 1990 s.

The Society for Worldwide Interbank Funds Transfers (SWIFT) has traditionally provided telecommunications links between the international banks to permit the exchange of payments information. Keen (1991) argues that SWIFT is important in creating a basis for entirely electronic financial transaction markets, and a bank that does not adopt the SWIFT standards and formats for funds transfers may be locked out of a wide range of core electronic financial services. Several studies describe successful applications of shared networks, including shared automatic teller machine (ATM) networks (Banker and Kauffman, 1990; Clemons, 1990), airline computerized reservation systems (CRS) (Copeland and McKenney, 1988), and wholesale distribution systems (Clemons and Row, 1988). Other well known shared networks include the securities settlement system that operates after financial market trades are made (McAndrews, 1992; Weiss, 1986), and credit card switching and transaction confirmation systems 
(Steiner and Teixeira, 1990).

Telecommunications technology changes the nature of competition significantly. By networking, firms that operate on a national basis may achieve massive economies of scale, in which average costs decrease as the size of operations and transactions volume increase. They can also deliver high levels of customer service by offering comprehensive geographic coverage. Because a nation-wide network can rarely be justified without a large customer base and volume of transactions to spread the costs, many firms have turned to one form or another of shared networks as an answer to their business problems. Each participant only needs to make a unit investment in local network facilities to achieve the same level of coverage or service to customers that the largest firms in the industry can provide.

In addition to economies of scale, shared networks exhibit positive network externalities for the users: the utility that a member derives from a network increases as other firms join the network (Rohlfs, 1974). The participation of new members in a shared network, thus, may induce other firms to adopt or participate. Because of network externalities and economies of scale, the owner of a shared network also has an incentive to expand. On the demand side, as the network grows those firms that have not adopted the shared network will come under increasing pressure from their customers. As suggested by Clemons (1990), scale economies and network externalities provide incentives for outsourcing, and are the principal forces leading to industry 
rationalization of shared services. But once the network bandwagon has begun to roll, few firms will be able to ignore it, even though participation in the network will only buy competitive parity.

In the financial services arena, the growth of shared electronic banking networks has been especially significant. In fact, electronic banking network evolution is heading from a world of regionally and nationally shared networks -- some of which directly compete with one another for customers -- towards universal access that will create scale economies that were not possible in the past (Kauffman and Theisen, 1990). The two largest national electronic banking networks, CIRRUS and PLUS, are the best known examples. Because large-scale, off-site deployment of ATMs is hard to justify without a universal card base, many depository financial institutions have turned to shared national ATM networks to offer customers greater access to their bank accounts and a high density of ATM locations (Silber 1986). This also offers the bank an opportunity to earn interchange revenue, when other banks' customers transactions require value-added switching.

In this paper, we investigate the adoption and diffusion pattern of telecommunications networks through an empirical analysis of the growth of PLUS and CIRRUS. This context for research is interesting because PLUS and CIRRUS have competed head-to-head throughout the United States, while offering relatively undifferentiated network services. Individual diffusion patterns are examined to verify if 
the S-shaped growth curve hypothesis still holds.

\section{LITERATURE}

In this section, we briefly review prior studies related to the diffusion and adoption of innovations and telecommunications networks, and several diffusion models suggested in the literature. The review focuses on the hypothesis that the growth curve of a telecommunications network is likely to be S-shaped.

\subsection{Innovation Diffusion and Adoption}

Research on diffusion and adoption of innovations has dealt with issues such as the growth pattern of adoption, the categorization of adopters, and the individual adoption process. The nature of diffusion of telecommunications technology can also be viewed from the perspective of traditional innovation diffusion theory (Gurbaxani, 1990).

Rogers (1983) categorized innovation adopters according to their relative innovativeness. The analysis proposed by Rogers assumes that the non-cumulative adopter distribution over time takes the form of a bell-shaped curve. A classification results from the division of the normal adopter distribution into categories based on the mean time of adoption and the standard deviations of those times. The growth pattern of the cumulative number of adopters corresponding to the bell-shaped distribution is an 
S-curve, which has been used successfully in the literature to characterize the diffusion process of many innovations.

Rogers' categorization, however, is not without limitations. Mahajan, Muller, and Srivastava (1990) pointed out that the assumption that all innovations follow a normal distribution diffusion pattern is questionable; in many situations innovation adoption patterns are likely to exhibit non-normal distributions. And in spite of the method's simplicity, Rogers provided no empirical or analytical justification of why the size of the adopter categories should be the same for all innovations. Mahajan, Muller, and Srivastava further proposed using the Bass diffusion model as a basis for adopter categorization. It subsumes the advantageous features of Rogers' method, and resolves some of its limitations. However, the cumulative adopter distribution of the diffusion model proposed by Bass (1969) was also an S-shaped curve.

Brancheau and Wetherbe (1990) confirmed the hypothesis that the cumulative adopter distribution for spreadsheet software traces a sigmoidal pattern over time. This hypothesis follows from the communication-based view of innovation diffusion with its emphasis on individual adoption decision making. In their study, the logistic function was compared to the linear function, and as hypothesized, the logistic function fit the data better.

The rate at which innovations are adopted by firms also constitutes an important 
part of the research in the economics literature. The most widely tested theory of the diffusion of innovation was advanced by Mansfield $(1961,1968)$. He argued that diffusion of an innovation throughout an industry follows a logarithmic curve. That is, the growth over time in the number of firms having adopted an innovation should conform to a logistic function, an S-shape growth curve. Since the pioneering work of Mansfield, various models have been proposed to represent the time pattern of technological changes, and used for technological forecasting. Some of the well known models include the imitation model suggested by Fisher and Pry (1971) and the Gompertz curve (Hendry, 1972; Martino, 1975). Both have the characteristic S-shaped pattern.

Essentially, the differences in various S-shaped curves derive from the steepness of the curve and the inflection point at which the rate of maximum growth occurs. The Gompertz curve and the Fisher-Pry model have a fixed inflection point, but the FisherPry model has the additional constraint of being symmetrical about the inflection point. Sharif and Islam (1980) argued that technologies tend to follow a predictable pattern of growth that can reasonably be described by S-shaped curves. They proposed that the more flexible Weibull distribution function be used to accommodate different patterns of technological growth. (There are several other innovation diffusion models proposed in the marketing literature, but these are beyond the scope of this study. Interested readers can refer to an extensive review of innovation models provided in Mahajan, Muller, and Bass (1990).) 
On the basis of the perspectives offered by the innovation diffusion literature, the growth pattern of a telecommunications network should also be an S-shaped curve.

\subsection{The Diffusion Pattern of Telecommunications Networks}

Theoretical Foundations. The focus of theoretical research on network externalities in the telecommunications context has been on the positive demand side externalities. Positive externalities often occur in the diffusion of innovations or standards: the value of adopting an innovation or standard depends on how many others adopt it (Dybvig and Spatt, 1983). Thus, the probability that an individual firm will adopt a telecommunications network also should be a non-decreasing function of the number of existing adopting firms. Because of scale economies and network externalities, the dynamics of industries subject to network externalities are fundamentally different from those of conventional industries (Katz and Shapiro, 1986a \& 1986b). Network goods have a greater tendency towards monopoly (or greater concentration) than services that do not generate externalities, and the strength of the network externalities that accrue from an existing installed base may lead to a bandwagon effect that results in social choices of inferior network technologies (Farrell and Saloner, 1986). (The eighttrack auto cassette tape player is a good illustration of this idea.)

In terms of the diffusion pattern for network goods, the literature has failed to reach a conclusion. Artle and Averous (1973) demonstrated that under certain 
conditions, the resulting growth process is a logistic curve, a special case of S-shaped curves. Markus (1987) suggested that modifications to the traditional S-curve are required to account for "interactive communication media", e.g., telephones, electronic mail, and facsimile machines. She argued that communication media, in general, face start up problems and the prospect of outright failure in the early stages. On the other hand, the adoption of communication media becomes progressively more attractive, the more it has been adopted by others. Therefore, she argued that the diffusion curve for successful interactive communication technologies is exponential rather than S-shaped.

Cabral (1990) presented a dynamic economic model of adoption of an innovation when there are network externalities. He concluded that if network externalities are strong, the adoption path may be discontinuous. He showed analytically that the adoption path may include a catastrophe point. This is in sharp contrast with the case of diffusion with no network externalities, where the adoption is presumed to be a smooth function. In particular, he argued that a steep S-shaped adoption path can be interpreted as an approximation to a discontinuity in the adoption path.

Empirical Findings. In an empirical application, Chaddha and Chitgopekar (1971) argued that the cumulative telephone growth in an area will be S-shaped if the saturation level -- defined as the maximum telephone market in an area, the ultimate level of adoption -- is constant over time. Under such circumstances, they suggested that a simple logistic function may be used to fit the available data to obtain forecasts of 
telephones. They also investigated the development of a class of models suggested by an application of the logistic curve to model the growth of residence telephones. Although the saturation level in a logistic function is constant, the authors' models allow the potential expansion of growth of saturation level over time to be a function of a number of economic and sociological variables, such as the number of households and average revenue per telephone.

A recent study by Gurbaxani (1990) examining the adoption pattern of BITNET, a telecommunications network linking computer users in academic institutions in the United States and in foreign countries, is most closely related to the present study in terms of the characteristics of network technology. BITNET, however, operates in a non-competitive environment, though other computer network alternatives exist. Gurbaxani hypothesized that the cumulative number of BITNET adopters grows according to an S-curve, which also implicitly assumes a constant saturation level. $\mathrm{He}$ tested two popular formulations of the growth process leading to an S-curve: the Gompertz curve and logistic curve. Estimating both curves with BITNET data, the author found that the logistic curve described the growth pattern very well, while the Gompertz curve did not.

Shared networks in the financial services industry frequently exhibit positive externalities, and late entrants at some point in time find that they must join the network in order to take advantage of them. Clemons and McFarlan (1984) have aptly 
characterized this as "hook up or lose out" competition. The level of network externality may be viewed as a source of business value and is an important determinant of shared network technology adoption. ${ }^{1}$ In the context of national electronic banking networks, the 1980 s witnessed tremendous growth and many instances of network consolidation and inter-organizational affiliation. Consequently, the saturation level of adoption of the networks may have been driven to a higher level. Robertson and Gatignon (1986) suggested that competition can have significant effects on technology diffusion.

\section{MODELING APPROACH}

In model fitting, one often has to balance between finding the best fitting curves and simple ones that fit well enough. We chose to use the Gompertz and logistic curves so that we can focus on important issues rather than on model generation. The Gompertz and logistic models are the two specifications most widely used to describe the S-shaped diffusion curve (Gurbaxani, 1990), and hence, their use allows for comparison of diffusion patterns of various innovation technologies. There are several alternative specifications of the Gompertz curve (Dixon, 1980; Martino, 1975; and Hendry, 1972) and the logistic curve (Hendry, 1972, Chaddha and Chitgopekar, 1971) presented in the literature. All feature three parameters for estimation. The variations of the Gompertz curve are essentially the same formula, and the different specifications of the logistic curve become identical with appropriate transformation. For ease of comparison, we use the formulations and specifications like those used in Gurbaxani's study of BITNET 
growth.

The Gompertz curve has the form:

$$
\mathrm{Y}_{\mathrm{T}}=\beta_{0} * \beta_{1} \wedge\left(\beta_{2} \wedge \mathrm{T}\right)
$$

where $Y_{T}$ represents the total number of network adopters up to time $T, B_{0}, \beta_{1}$, and $\beta_{2}$ are the parameters to be determined, $\mathrm{T}$ is time, and $\wedge$ is the exponentiation operator. The logistic curve, which utilizes the same variables, can be expressed as:

$$
\mathrm{Y}_{\mathrm{T}}=1 /\left(\beta_{0}+B_{1}{ }^{*} \beta_{2} \wedge \mathrm{T}\right)
$$

where $Y_{T}$ is the number of existing network adopters up to time $T$, and $B_{0}, B_{1}$, and $B_{2}$ are the estimation parameters.

For forecasting purposes, the focus is on determining the steepness of the curve, the point at which the marginal growth rate of adoption is maximized, and the saturation level of adoption. For the Gompertz curve expressed as equation (1), $\mathrm{Y}_{\mathrm{T}}$ is an increasing S-curve which approaches the saturation level of adoption, $\beta_{0}$, as $T \rightarrow \infty$ when $B_{1}$ and $\beta_{2}$ are between 0 and 1 . The curve reaches its maximum growth rate when $Y_{T}=B_{0} / e=$ $\mathrm{Y}^{\max } / \mathrm{e}(\mathrm{e}=2.718)$, which is $36.7 \%$ of its saturation level (Martino, 1975).

For $\beta_{1}>0$ and $0<\beta_{2}<1$, the logistic curve expressed as equation (2) is also an Scurve, which approaches the saturation level of network growth, $1 / \mathbb{B}_{0}$, as $T \rightarrow \infty$. The maximum growth rate is achieved when $Y_{T}=1 / 2 \beta_{0}=Y^{\max } / 2$, which is half the saturation level. Like many of the S-curve models, the growth rate function is symmetric around 
the inflection point, where the growth rate is maximized.

When the growth pattern is modeled using saturation models such as the

Gompertz and logistic models, a constant saturation level over time is assumed. A good fit of one of these models to the CIRRUS and PLUS data would provide evidence in support of an S-shaped growth curve and a constant saturation level. This would also imply that telecommunications networks in the financial services industry are not different from traditional innovations in terms of their growth patterns, despite pervasive competition in the industry.

As suggested by Gurbaxani (1990), determination of the appropriate functional form of the growth curve also has important managerial implications. The Gompertz curve, for example, exhibits a more constant rate of growth in later stages than the logistic curve, and attains its maximum rate of growth at an earlier stage $\left(\right.$ at $\mathrm{Y}_{\mathrm{T}}=\mathrm{Y}^{\mathrm{max}} / \mathrm{e}$ for the Gompertz curve versus $\mathrm{Y}_{\mathrm{T}}=\mathrm{Y}^{\max } / 2$ for the logistic curve). If an S-curve does not fit as suggested in the innovation diffusion literature, however, more sophisticated models may need to be developed to describe the growth pattern.

\section{THE EVOLUTION OF SHARED ATM NETWORKS}

Shared electronic banking networks started as proprietary networks owned by individual banks, and accessible only by that bank's customers. When the banks realized 
that there were benefits associated with sharing ATMs, they first created locally and regionally shared networks, and later expanded their scope to reach the national and international levels. Due to the incentives producers have to expand their networks, there has been a marked trend toward network consolidation among regional and national networks (McAndrews, 1991). What were the contexts in which national networks were established? What characterized the growth of national networks? Where are they headed? We next provide a brief description of the evolution of shared electronic banking networks. Then we present some background information for the CIRRUS and PLUS banking networks, including a time-line of major network events.

\subsection{Electronic Banking Network Evolution}

Felgran and Ferguson (1986) reviewed the various phases in the evolution of ATMs beginning with proprietary networks, where a single owner/operator deploys the technology to service just its own customer, to widely shared networks, which offer access to any entrant willing to pay the fee and to adopt the standard operating protocols. They suggested that this evolution was a function of changing cost structures and marketing strategies over time. They further predicted that networks of ATMs would continue to progress towards greater public access unless hampered by regulatory constraints. Felgran and Ferguson (1986) also characterized the evolution of ATM networks in five phases: proprietary, shared, multiple memberships, direct links, and universal (or global) sharing. 
Kauffman and Theisen (1990) investigated ways that banks use ATM services and membership in ATM networks as strategic marketing tools and concluded that the framework proposed by Felgran and Ferguson (1986) still makes sense. They suggested that further network evolution is towards universal access and expanding the service of the ATM of the 1980s for a broader role as a marketing channel for financial and nonfinancial services in the 1990s. Kauffman and Theisen also provided an overview of how the changes occurred, and what kind of service scope changes would be likely to result as electronic banking moves in the direction of universal access.

\subsection{CIRRUS}

CIRRUS was organized in 1982 by ten banks that wanted to expand their regional networks to achieve national coverage. The largest among them included BayBanks (Massachusetts), Manufacturers Hanover (New York), Mellon Bank (Pennsylvania), and First Chicago (Illinois) (Gifford and Spector, 1985). (For a discussion of the issues related to the design and implementation of the CIRRUS banking network, the interested reader should see Gifford and Spector (1985).)

In September 1987, CIRRUS and MasterCard announced their intentions to form a union, while maintaining CIRRUS as a trademark for shared ATM services. Prior to that time MasterCard operated its own shared network called MasterTeller, which would ultimately compete for locations with VISA's network, as well as CIRRUS and PLUS. 
The subsequent acquisition of CIRRUS by MasterCard in January 1988 had a major impact on the network's members. By 1988 , about $85 \%$ of the members of the MasterTeller network, with more than 800 members and 10,000 ATMs, had chosen to participate in CIRRUS. When it became clear that consumer recognition of CIRRUS dominated MasterTeller, MasterCard moved to phase out MasterTeller in 1989. The acquisition resulted in further economies of scale and an expanded membership base, and hence, CIRRUS has realized broader geographic coverage and cost savings. In 1990, the number of members had reached about 5400 , two orders of magnitude larger than when CIRRUS was established.

Table 1 presents data on the growth of CIRRUS ATM locations. CIRRUS grew steadily in terms of the cumulative number of ATM locations until mid 1990, when the network appeared to take off. Figure 1 presents a time line of CIRRUS growth with brief annotations of the major events.

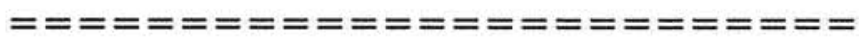

$$
\begin{aligned}
& \text { Insert Table } 1 \text { and Figure } 1 \text { About Here }
\end{aligned}
$$

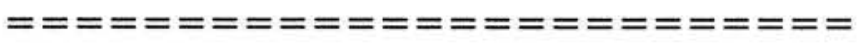

\subsection{PLUS}

PLUS was originally conceived in 1977 by D. Dale Browning, then president of 
Colorado National Bank, as a means of competing with bigger banks (Snitzer, 1987). By 1979, more than $15 \%$ of the banks in Colorado, New Mexico, and Wyoming had joined the network. In April 1982, 26 leading U.S. commercial banks from around the U.S. incorporated the PLUS System for the specific purpose of establishing a national shared ATM network as a not-for-profit membership organization (PLUS Annual Report, 1988). Since then, the number of financial institutions participating in PLUS has dramatically increased from the original 26 in 1982 to about 3,500 in 1990. The principal owning members include Bank One (Ohio), the Philadelphia National Bank (Pennsylvania), and Chase Manhattan Bank (New York). Processor members include Mellon Bank (Pennsylvania), and two regional shared electronic banking networks (the New York Cash Exchange, with primary operations in New York City, and the Star System of California). The affiliation of VISA U.S.A. with PLUS in 1987 further enhanced the worldwide recognition of the PLUS network. By the end of 1991, PLUS had linked nearly 50,000 ATMs in the U.S. and more than 70,000 ATMs worldwide.

Table 2 presents data on the growth of PLUS ATM locations. Figure 2 presents a time line of major events that occurred as the PLUS network grew. As can be seen in Figure 2, PLUS grew slowly but steadily until May 1987, when the growth rate increased. In May 1990, network growth took off.

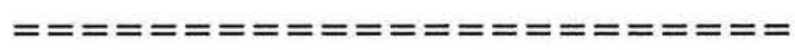

Insert Table 2 And Figure 2 About Here

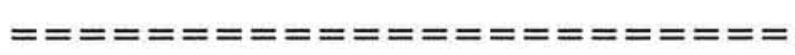




\subsection{National Network Duality}

McAndrews (1992) suggested three factors that distinguish national level shared electronic banking networks and enable predictions to be made about whether one or the other will become dominant:

(1) a clear technological edge;

(2) a large and growing installed base of member firms; and,

(3) an appropriate ownership and governance structure.

As a result of the firm's interest in joining a network that will become the industry standard, either a bandwagon effect or excess inertia in the growth of networks will arise (Farrell and Saloner, 1986; McAndrews, 1992). A bandwagon effect can occur if one network achieves a larger installed base for some reason, and everyone then believes that it will become dominant, and so rushes to join it. Excess inertia can occur if everyone would be better off with any of the networks that are in contention, but no one is willing to commit to any one network for fear that it will make the wrong choice.

When firms judged CIRRUS and PLUS in terms of the three distinguishing factors above, it appeared to them that neither one nor the other would become dominant. (In fact, we think that this view still holds, but for reasons that we will explain shortly, which network is larger is of less concern now than at any time in the past.) By 1990, there was growing evidence that the size of the CIRRUS and PLUS networks had 
grown into the range of market saturation. Almost every ATM in the U.S. was connected with one of the national networks. To achieve further network externalities and economies of scale, consolidations between the national networks were logical.

CIRRUS and PLUS used to have exclusive membership rules that prohibited their members from participating in other national networks. But an agreement to share ATMs by the two national ATM networks was finalized in 1989. Duality is the name given to this interchange agreement between CIRRUS and PLUS. Under duality, a member of one can accept transactions by cardholders from the other at a nominal fee (McAndrews, 1991). In the summer of 1990, the interface was activated, a move that could eventually double the size of the network ATM base available to customers in the U.S. because PLUS and CIRRUS members were allowed to join the other network.

\section{MEASURE SELECTION AND DATA COLLECTION}

We now present our rationale for selection of a specific measure of electronic banking network growth -- the number of ATM locations as opposed to the number of ATMs on the network. This supports our concept of technological diffusion in this research: the growth of links to CIRRUS and PLUS primarily among existing, but also among new locations. The reader should keep in mind that CIRRUS and PLUS themselves do not deploy ATMs. Instead, they link ATMs deployed by member banks. A description of the data set and the data collection process follows. 


\subsection{Measure Selection}

A key issue that we faced in conducting this research was to identify an appropriate metric for electronic network growth. We examined a number of candidate measures in terms of their adequacy in capturing the essence of the network size construct and usefulness for practitioners interested in making forecasts of network growth. The relative success of an ATM network may be measured by the number of cardholders, on-line ATMs, ATM locations, network members, or volume of network transactions. The number of cardholders and volume of network transactions depend on the acceptance and usage of the technology by consumers, who are influenced by brand recognition and marketing education programs. Using the number of network members as the measure has a potential flaw: counting member banks aggregates huge national banks and small community banks, which are likely to contribute differently to the perceived externality value of the shared network.

The number of on-line ATMs and ATM locations are better alternative measures of the growth of ATM networks. But, because a bank can deploy anywhere from one to ten ATMs at a single location, it seems as though using the number of machines would not represent the locational convenience from which the externalities actually arise. In addition, we learned through our field study research that the number of locations may be the only data that is widely available. Fortunately, quarterly, seasonal or twice yearly granularity of data on the number of ATM locations is better suited to econometric 
analysis than some of the other candidate measures, which are most often tracked on annual basis. Thus, we employ the number of ATM locations in this study to measure the diffusion and growth of the national ATM networks.

\subsection{Data Collection}

For historical data on the number of ATM locations, we acquired all published location directories from 1984 to 1992 for CIRRUS and PLUS with the assistance of local banking firms, regional ATM network organizations, and CIRRUS and PLUS themselves. We also acquired published annual reports of CIRRUS and PLUS, and their respective parent organizations, to assist us in understanding their background.

We later hired a group of eight undergraduate students to count the number of ATM locations by state and by network in three supervised sessions. ATM locations for both CIRRUS and PLUS were then recounted by state to ensure data quality. Finally, for each state, the growth trend in ATM locations was visually checked for discrepancies. Suspicious data were identified and discrepancies were resolved. All numbers for state ATM locations in a particular location directory were then aggregated to the national level. Because CIRRUS and PLUS location directories published after May 1990 include dual ATM locations, we obtained data on the number of ATM locations without duality from CIRRUS and PLUS to avoid the problem of double counting. 


\section{RESULTS AND DISCUSSION}

We now examine the underlying growth pattern of CIRRUS and PLUS by performing formal statistical analysis. We first fit the Gompertz and logistic curves with full data sets for CIRRUS and PLUS, and briefly discuss the results of the analysis. Then we re-estimated both curves with revised data sets, omitting those observations after the second quarter of 1990 , when the move to duality occurred.

\subsection{Results of Preliminary Analysis}

Non-linear least squares estimation in LIMDEP 6.0, an econometric software package, was used to estimate the Gompertz and logistic curves, and to determine their parameters, $\beta_{0}, B_{1}$, and $\beta_{2}$. An S-curve model is considered to fit well if the following criteria are met:

(1) the minimizing function converges and the minimum of the function can be found;

(2) the $\mathrm{R}^{2}$ value is high, although it is only a necessary, but not a sufficient condition for a good fit;

(3) the t-tests for the estimated parameters are significant;

(4) the implied saturation level is reasonable; and,

(5) residual analysis does not reveal a systematic pattern.

For inter-model comparison, we use sum of residual squares as the basis to determine which model fits better. 
The Gompertz Curve. The parameter estimation results for the Gompertz curve using non-linear least squares are presented in Tables 3 and 4 for CIRRUS and PLUS, respectively. Figures 3 and 4 present a graphical depiction of the fit.

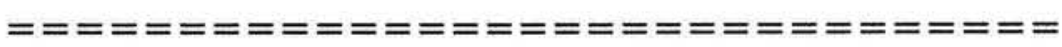

$$
\begin{aligned}
& \text { Insert Tables 3-4, and Figures 3-4 About Here }
\end{aligned}
$$

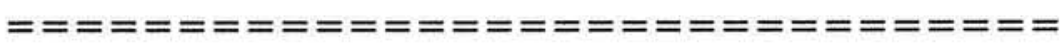

The $\mathrm{R}^{2}(.9943)$ of the regression is quite high for CIRRUS, and all three estimated coefficients $\left(B_{0}=115960, B_{1}=.0428\right.$, and $\left.\beta_{2}=.989\right)$ have significant t-statistics (at the level $\mathrm{p}=.001$ ). The estimation results indicate a saturation level of ten thousand $\left(B_{0}=11596\right)$ ATM locations. Overall, the Gompertz curve describes the growth pattern well, and the hypothesis that network growth follows the Gompertz curve is supported.

For PLUS, $R^{2}=.994$ and all three estimated coefficients $\left(B_{0}=96483, \beta_{1}=.024857\right.$, and $B_{2}=.9256$ ) have significant $t$-statistics (at the level $p=.001$ ). The estimation results indicate a saturation level of close to ten thousand ATM locations. Hence, we cannot reject the Gompertz curve hypothesis for the PLUS data.

The Logistic Curve. The parameters of the logistic curve, $B_{0}, B_{1}$, and $\beta_{2}$, were also estimated using non-linear least squares. For both CIRRUS and PLUS, we were not able to obtain an estimation that fits the growth data well. In all instances, the 
estimation procedure either could not locate the function's minimum, it failed to converge, or the models had low $\mathrm{R}^{2}$ values. Thus, it appears that the logistic curve does not provide a good fit, and hence, we cannot accept the logistic curve hypothesis.

Linear and exponential models were also fitted for comparison. Although $\mathrm{R}^{2}$ values are high and t-tests for parameters are significant for both CIRRUS and PLUS, residual analysis revealed that both models did not describe the growth patterns well (e.g., Durbin-Watson values $<.5$ in all cases). Further inter-model comparison using sum of residual squares indicated that the linear model fits slightly better than exponential model, but both did not come close to the Gompertz model. Given that the Gompertz curve describes the growth patterns of both networks well, the S-curve hypothesis is supported.

\subsection{Regime Change and Revised Estimation}

Although we suspect that there might have been a dramatic change in saturation level due to duality, we found that the Gompertz model fits well. An examination of Figures 1 and 2 reveals that the growth of CIRRUS and PLUS had slowed down by the first half of 1990, and then resumed a faster pace. These growth rates coincided with the implementation of duality, allowing the members of CIRRUS and PLUS to join the other network. As described in section 4, CIRRUS and PLUS began to share their ATM locations in the summer of 1990 . The resulting regime change appears to have greatly 
influenced the growth pattern of both CIRRUS and PLUS.

Although the Gompertz and logistic curves assume a constant saturation level, they may nevertheless fit well the growth curve of an innovation that has a dynamic saturation level. Diffusion with a dynamic ceiling may still assume a sigmoidal form, and pass the tests of model fit. As suggested by Mahajan and Peterson (1985), the implication of using a conventional diffusion model when there is a dynamic saturation leads to erroneous parameter estimates, although not necessarily low $\mathrm{R}^{2}$ values or insignificant t-statistics for parameters. Thus, although the growth patterns of both networks pass the tests of the Gompertz model fit, we cannot reject that the hypothesis that the regime change had led to a higher saturation level. In order to test if there was indeed a regime change, we re-estimated both the Gompertz and logistic models for CIRRUS and PLUS using a revised data set. The revised CIRRUS and PLUS data set included all data up to the second quarter of 1990.

The Gompertz Curve. The revised estimation results for the Gompertz curve are presented in Tables 5 and 6 for CIRRUS and PLUS, respectively. Figures 5 and 6 present a graphical depiction of the fit. The $\mathrm{R}^{2} \mathrm{~s}$ of the regressions are high for both CIRRUS (.997) and PLUS (.985). For CIRRUS, all three estimated coefficients $\left(\beta_{0}=39967, \beta_{1}=.103\right.$, and $\left.\beta_{2}=.977\right)$ are highly significant $(p=.001)$, and the estimation results indicate a saturation level of about 40,000 ATM locations, as opposed to 115,960 estimated earlier with the full data set. The curve is at its maximum growth rate 
(inflection point) when $\mathrm{Y}_{\mathrm{T}}=B_{0} / \mathrm{e}=\mathrm{Y}^{\max } / \mathrm{e}=14,716$, which is $36.7 \%$ of its saturation level. With the Gompertz curve as its growth curve, obviously CIRRUS had passed its maximum growth rate, which occurred in late 1987, and was driving towards maturity in mid 1990, already with about $60 \%$ of the saturation level.

$$
\begin{aligned}
& ==\mathrm{=}=\mathrm{=}=\mathrm{=}=\mathrm{=}=\mathrm{=}=\mathrm{=}=\mathrm{=}=\mathrm{=}=\mathrm{=}=\mathrm{=}=\mathrm{=} \\
& \text { Insert Tables 5-6, and Figures 5-6 About Here }
\end{aligned}
$$

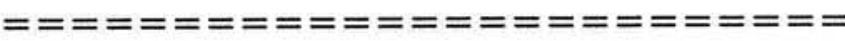

To see if the Gompertz model has stability and predictive validity, we employed the commonly used one-step-ahead forecasting technique. We first estimated the Gompertz curve using as few as four observations, then used the derived parameters to forecast the next observation. The process continued until the last observation. We found that the Gompertz model became stable in terms of all estimated parameters after the eighth observation (May 1987), until after May 1990. This result is consistent with prior studies (Heeler and Hustad, 1980; Srinivasan and Mason, 1986), which suggest that stable and robust parameter estimates can be obtained only if the data under consideration include the peak of the noncumulative adoption curve. Also, the model performed well in onestep-ahead forecasting until after duality, when the Gompertz curve underestimated the growth. Further statistical tests suggest that the predicted cumulative number of ATM locations would reach 26,039 in December 1990 (standard error (S.E.)=1549), 28,859 in December 1991 (S.E.=1494), and 30,661 in September 1992 (S.E.=1415), all at the 
$\mathrm{p}=.001$ level. All observations after duality but one, i.e., December 1990, fall outside of the $95 \%$ confidence intervals. Clearly, the basic Gompertz curve with the revised data set failed to capture the jump in growth, which we argue is due to the regime change by duality.

To estimate the effect of duality on saturation level, we used a dummy variable, $B_{0}$, for observations after duality to represent the change in saturation level. The model thus incorporates some notion of dynamic ceiling. We estimated the modified 4parameter model and obtained a improved fit with $\mathrm{R}^{2}=.996$, and all parameters highly significant $\left(B_{0}=73,884, B_{0}{ }^{\prime}=40,410, \beta_{1}=.02339\right.$, and $B_{2}=.9876$ at $\left.p=.001\right)$. Assuming that $B_{1}$ and $B_{2}$ remain constant throughout the time period being modeled, the regime change appear to increase the saturation level by 40,410 ATM locations.

All three estimated coefficients are also significant for PLUS, and the predicted saturation level is on the order of 66,000 ATM locations, as opposed to 96,500 with full data set. The curve would reach its inflection point when $\mathrm{Y}_{\mathrm{T}}=B_{0} / \mathrm{e}=\mathrm{Y}^{\mathrm{max}} / \mathrm{e}=24,280$, which is again $36.7 \%$ of its saturation level. If the Gompertz curve with its estimated parameters represents the growth pattern well, PLUS in mid 1990 (21,643 ATM locations in May 1990) was well on its way to its maximum growth rate.

Again, we checked if the Gompertz model estimated using the revised PLUS data set has stability and predictive validity. We found that the Gompertz model was unstable 
in terms of all estimated parameters before and after duality, and hence, did not perform well in one-step-ahead forecasting, presumably due to fewer observations during the time period being modeled. Assume that the estimated model using revised PLUS data set was the correct model, the Gompertz curve also underestimated the growth after duality. Further statistical tests, however, suggest that all observations after duality fall in the confidence intervals constructed using two S.E. Hence, we cannot infer with confidence that there is a jump in network growth.

When a dummy variable was used for observations after duality was in effect, we were not able to obtain a significant model, despite a high $\mathrm{R}^{2}(.996)$. In particular, $\beta_{0}$, which represents the change in saturation level is not significantly different from zero. One plausible reason is that the assumption that $\beta_{1}$ and $\beta_{2}$ remain constant before and after duality did not hold. The regime change could have caused the change of the two parameters, in addition to raising the saturation level to a higher level. Hence, it is possible that the model does not fit when there was in effect a change in saturation level.

The Logistic Curve. We also re-estimated the logistic curves for CIRRUS and PLUS. Tables 7 and 8 present the estimation results for CIRRUS and PLUS, respectively. Figures 7 and 8 present a graphical depiction of the fit. The $\mathrm{R}^{2} \mathrm{~s}$ of the regressions are very high for both networks (.996 for CIRRUS and .989 for PLUS). All estimated parameters are significant for CIRRUS $\left(B_{0}=.0000333, B_{1}=.000191\right.$, and $\beta_{2}=.954$ ) at $\mathrm{p}=.001$ level, with an estimated saturation level of about 30,000 ATM 
locations. The maximum growth rate was achieved in late 1987 when the number of ATM locations grew to 15,000 , which is half the saturation level. In 1990, CIRRUS had 24,140 ATM locations, about $80 \%$ of the upper bound for network adoption.

All estimated parameters are also significant for PLUS $\left(\beta_{0}=.0000313, \beta_{1}=.000397\right.$, and $B_{2}=.757$ ) at $p=.001$ level, with an estimated saturation level of about 32,000 . These values represent a reasonable upper bound for the size of each network. The growth of the PLUS network reached its inflection point when $Y_{\mathrm{T}}=1 / 2 \beta_{0}=Y^{\max } / 2=16,000$, in the fourth quarter of 1988 , and reached $68 \%$ of the estimated saturation level of adoption by May 1990.

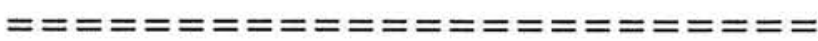

$$
\begin{aligned}
& \text { Insert Tables 7-8, and Figures 7-8 Here }
\end{aligned}
$$

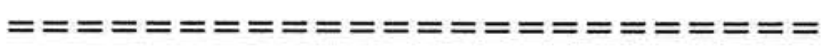

Although the logistic models failed to fit CIRRUS and PLUS growth curves with full data sets, they performed very well with the revised data sets. However, the logistic models did not have predictive validities, especially after duality when the network growth of both CIRRUS and PLUS were seriously underestimated. Further statistical tests suggest that all observations after duality fall outside of the confidence intervals constructed using two S.E. Hence, the logistic curve estimated using the revised data set failed to capture the jump in growth after duality. 
Using a dummy variable for observations after duality, we were not able to obtain a significant model with CIRRUS and PLUS data. Hence, we were not able to obtain an estimate of the change of saturation level associated with duality. As was discussed earlier, it might be due to the unreasonable assumption that $\beta_{1}$ and $\beta_{2}$ remain constant before and after duality. In fact, the effect of duality might have caused the change of all parameters, including the saturation level. Although we could not estimate the change of saturation level associated with duality

The results of our revised estimation suggest that the move to duality has had a great impact on the growth pattern of both CIRRUS and PLUS. It appears that the saturation levels have been increased through this change, and this cannot be captured by the conventional S-curve saturation models. Our statistical analysis indicates that both the Gompertz and logistic curves fit well when data associated with the regime change have been omitted.

\section{IMPLICATIONS AND CONCLUSIONS}

Given that the Gompertz model fit the growth data of both networks well, we cannot reject the general S-curve hypothesis. Finding a conventional diffusion model that fits, however, does not rule out the possibility that there might have been a change in saturation level or other diffusion parameters. Our analysis provide some evidence of a regime change due to duality, and indicate that the assumption of a constant saturation 
may not hold in presence of competition. We the effect of network externalities by significantly estimating the change in saturation level, which conventional diffusion models have failed to capture.

Within a time frame in which there is no significant regime change or saturation level variation, conventional S-curve models describe the growth very well. In our analysis with revised CIRRUS data set, we found that the estimated model had reasonable stability and predictive validity. Hence, it is possible to estimate an appropriate S-shaped growth model to depict the successive increases in the number of the adopters, identify the point where the maximum growth rate occurs (and where marginal network externalities are maximized ), and predict the continued development of a diffusion process. These information will have value for managerial planning, and can offer normative guidelines for how an innovation should be diffused (Mahajan and Muller, 1979). For example, management can devise plans to increase the saturation level of adoption for the network, exploit the benefits of network economies of scale, and ensure that the adoption process of the network be self-sustaining.

Managers can also focus on identifying potential adopters, particularly large banks whose adoption can significantly increase the level of network externalities and induce others to adopt. When a network has achieved the maximum growth rate and begins to mature (Hendry (1972) suggested that this occurs at about $88 \%$ of the saturation level.), management can plan for a strategic move to create an opportunity for a higher level of 
growth. Using the terms presented by Keen (1991), this can be achieved by identifying additional potential adopters or opening up a new service delivery channel to enhance the "reach" of the network, or by providing more differentiated network services to enhance the "range" of the network (Keen, 1991). Home banking services delivered through Prodigy would be a good example of increased reach, and being able to purchase theater tickets, postage stamps or obtain airline schedule information at an ATM would be good examples of range.

Network owner-operators have the incentive to grow and expand, and their strategic initiatives may cause profound regime change on the supply side. The implementation of duality in 1990 offers an example of a strategic move that have resulted in an accelerated network growth. There are several plausible explanations for the jump in network growth after duality. First, the implementation of duality might represent a regime change. Because the number of cardholders nearly doubled and ATM transactions were expected to grow dramatically, more ATM deployment would readily be justified, and thus more ATM locations would be made available by the banks. Second, the excess inertia discussed by Farrell and Saloner (1986) and McAndrews (1991) may have been overcome, and a bandwagon effect may have occurred because of duality. In the absence of a clearly dominant standard, banking firms struggle to choose the one that will become dominant. With the move to duality, the contention between the two network technologies might have been reduced, and thus firms rushed to adopt, thinking that the network would become the dominant industry standard. In effect, a firm could 
elect to join either CIRRUS or PLUS and receive the benefits of both.

Interviews with senior managers at CIRRUS and PLUS support the view that both networks seem to have gained equally from duality. By the third quarter of 1992, about $70 \%$ of CIRRUS members and some $80 \%$ PLUS members had dual links. Moreover, both networks have enjoyed an annual growth of about $80 \%$ in terms of transaction volumes ever since duality. The decision of both networks to cooperate has resulted in a larger joint customer base, and a tremendous amount of growth that will lead to more efficient production of electronic banking services nationwide.

The standard Gompertz and logistic S-curve specifications are not powerful enough to detect the regime change if there was any. There are several possible extensions to the Gompertz and logistic curves for further study. These include models that:

(1) are able to capture symmetric as well as asymmetric patterns with no restriction on the point of inflection;

(2) can capture time-varying parameters of adoption, including saturation levels; and,

(3) can incorporate additional explanatory variables such as product and market characteristics.

In particular, because conventional diffusion models are not able to model the interaction between competing network technologies, product substitute models, such as the one proposed by (Mahajan and Peterson, 1985), seem to be valuable. Further data collection 
is needed to model at the level of product class or to apply more advanced diffusion model for product substitutes.

The results of this study not only have implications for other telecommunications networks, such as SWIFT and credit card switching, but also for non-network products or technology standards subject to economies of scale and network externalities, such as computer operating systems (OS/2, UNIX, and MS-DOS), computer architecture design (RISC and SISC), and video standards (VHS versus Beta). The recent cooperation between major computer vendors offers a case in point. We caution the reader to note, however, that CIRRUS and PLUS are fundamentally identical technologies, while other technology standards may be quite different.

\section{ENDNOTES}

1. Although senior executives in electronic banking never use the term "network externalities", we have ample evidence of their existence from interviews conducted in field studies of CIRRUS and PLUS (Linda Snelgrove, CIRRUS Systems Inc., and Lucy Rognes, PLUS Systems Inc.); MAC/Metroteller in New York (Joseph Wolfson, MAC/Metroteller); CashStream and MAC in Pennsylvania (Joseph Pendleton III, Meridian Bancorp); and the Yankee 24 electronic banking network in New England (Richard Yanak and Richard Symington, New England Network, Inc., and the results of a survey of more than 500 member banks 
(Kauffman and Wang, 1992)). 
Center for Digital Economy Research Stern School of Business

Working Paper IS-92-32 


\section{REFERENCES}

Artle, R. and C. Averous (1973), "The Telephone System as a Public Good: Static and Dynamic Aspects," Bell Journal of Economics and Management Science, Vol. 4, No. 1 (Spring), 89-100.

Banker, R. D., and Kauffman, R. J. (1990), "A Case Study of Electronic Banking Operations at Meridian Bancorp," Information and Software Technology, Vol. 33, No. 3 (April).

Brancheau, J. C., and J. C. Wetherbe (1990), "The Adoption of Spreadsheet Software: Testing Innovation Diffusion Theory in the Context of End-User Computing," Information Systems Research, Vol. 1, No. 2 (June), 115-143.

Cabral, L. (1990), "On the Adoption of Innovations with Network Externalities," Mathematical Social Sciences, Vol. 19, 299-308.

Canright, C. (1988), "Seizing the Electronic Information Advantage," Business Marketing (January), 81-86.

Chaddha, R. L. and S. S. Chitgopekar (1971), "A Generalization of the Logistic Curves and Long-range Forecasts (1966-1991) of Residence Telephones," Bell Journal of 
Economics and Management Science, Vol. 2, No. 3 (Autumn), 542-60.

Clemons, E. K. (1990), "MAC-Philadelphia National Bank's Strategic Venture in Shared ATM Networks," Journal of Management Information Systems, Vol. 6, No. 5 (Summer), 525.

Clemons, E. K., and McFarlan, W. F. (1984), "Hook Up or Lose Out," Harvard Business Review, 1984.

Clemons, E. and M. Row (1988), "McKesson Drug Company: A Case Study of Economost-A Strategic Information System," Journal of Management Information Systems, Vol. 5, No. 1 (Summer), 36-50.

Copeland D. G. and J. L. McKenney (1988), "Airline Reservations Systems: Lessons from History," MIS Quarterly, Vol. 12, No. 3 (September), 353-370.

Dixon, R. (1980), "Hybrid Corn Revisited," Econometrica, Vol. 48, No. 6, (September), 1451-61.

Dybvig, P. H., and C. Spatt (1983), "Adoption Externalities as Public Goods," Journal of Public Economics, Vol. 20, 231-247. 
Farrell, J., and G. Saloner (1986), "Installed Base and Compatibility: Innovation, Product Preannouncements, and Predation," American Economic Review, Vol. 76, No. 5 (December), 940-955.

Felgran, S. D., and R. E. Ferguson (1986), "The Evolution of Retail EFT Networks," New England Economic Review (July-August), 42-56.

Fisher, J. C. and R. H. Pry (1971), "A Simple Substitution Model of Technological Change," Technological Forecasting and Social Change, Vol. 2 (May), 75-88.

Gifford, D. and A. Spector (1985), "The CIRRUS Banking Network," Communications of the ACM, Vol. 28, No. 8 (August), 798-807.

Gurbaxani, V. (1990), "Diffusion in Computing Networks: The Case of BITNET," Communications of the ACM, Vol. 33, No. 12 (December), 65-75.

Heeler, R. M. and T. P. Hustad (1980), "Problems in Predicting New Product Growth for Consumer Durables," Management Science, Vol. 26 (October), 1007-20.

Hendry, I. C. (1972), "The Three-Parameter Approach to Long Range Forecasting," Long Range Planning, Vol. 51 (March), 40-5. 
Katz, M., and C. Shapiro (1986a), "Technology Adoption in the Presence of Network Externalities," Journal of Political Economy, Vol. 94, No. 4, 822-841.

Katz, M., and C. Shapiro (1986b), "Product Compatibility Choice in a Market with Technological Progress," Oxford Economic Papers, Vol. 38, 146-165.

Kauffman, R. J. and M. B. Theisen (1990), "Automated Teller Machine (ATM) Network Evolution in American Retail Banking: What Drives it?" Working Paper, Center for Research on Information Systems, Stern School of Business, New York University (November).

Kauffman R. J. and Y. M. Wang (1992), "The Determinants of Shared Network Technology Adoption: The Case of Electronic Banking," Working Paper, Center for Research on Information Systems, Stern School of Business, New York University.

Keen, P.G.W. (1991), Shaping the Future: Business Design Through Information Technology, Cambridge, MA: Harvard Business School Press.

Mahajan, V. and E. Muller (1979), "Innovation Diffusion and New Product Growth Models in Marketing," Journal of Marketing, Vol. 43, No. 4 (Fall), 55-68.

Mahajan, V., E. Muller, and R. K. Srivastava (1990), "Determination of Adopter 
Categories by Using Innovation Diffusion Models," Journal of Marketing Research, Vol. 27, No. 1 (February), 37-55.

Mahajan, V., E. Muller and F. M. Bass (1990), "New Product Diffusion Models in Marketing: A Review and Directions for Research," Journal of Marketing, Vol. 54, No. 1 (January), 1-26.

Mahajan, V. and R. Peterson (1985), Models for Innovation Diffusion, Newbury Park, CA: Sage Publications.

Mansfield, E. (1961), "Technical Change and the Rate of Imitation," Econometrica, Vol. 29, No. 4 (October), 741-766.

Mansfield, E. (1968), Industrial Research and Technological Innovation, New York: W. W. Norton and Co.

Markus, M. L. (1987), "Toward a Critical Mass Theory of Interactive Media: Universal Access, Interdependence and Diffusion," Communication Research, Vol. 14, No. 5 (October), 491-511.

Martino, J. P. (1975), Technological Forecasting for Decision Making, New York: American Elsevier. 
MasterCard International Annual Report, 1990-1991.

McAndrews, J. J. (1991), "The Evolution of Shared ATM Networks," Business Review, Federal Reserve Bank of Philadelphia (May-June), 3-16.

McAndrews, J. J. (1992), "Network Business Value Externalities," in Perspectives on the Strategic and Economic Value of Information Technology Investments, R. D. Banker and R. J. Kauffman (eds.), Middleton, PA: Idea Group Publishers.

PLUS System Inc. Annual Report, 1988-1991.

Robertson T. and H. Gatignon (1986), "Competitive Effects on Technology Diffusion," Journal of Marketing, Vol. 50, No. 3 (July), 1-12.

Rogers, E. M. (1983), Diffusion of Innovations, New York, NY: Free Press.

Rohlfs, J. (1974), "A Theory of Interdependent Demand for a Communication Service," Bell Journal of Economics and Management Science, Vol. 5, 16-37.

Saloner, G. and A. Shepard (1991), "Adoption of Technologies with Network Effects: An Empirical Examination of the Adoption of Automated Teller Machines," Working Paper No. 577 (April), Massachusetts Institute of Technology. 
Sharif, M. N. and M. N. Islam (1980), "The Weibull Distribution as a General Model for Forecasting Technological Change," Technological Forecasting and Social Change, Vol. 18 (December), 247-56.

Silber, K. (1986), "Facing a New ATM Reality," Bank Systems and Technology, February, 26-28.

Snitzer, A. (1987), "Plastic Profits," Forbes (August 10), p. 116.

Srinivasan, V. and C. H. Mason (1986), "Nonlinear Least Squares Estimation of New Product Diffusion Models," Management Science, Vol. 5, No. 2, 169-78.

Steiner, T., and D. Teixeira (1990), Technology in Banking: Creating Value and Destroying Profits, New York: Dow Jones - Irwin.

Weiss, D. M. (1986), After the Trade is Made: Processing Securities Transactions, New York, NY: New York Institute of Finance/Simon and Schuster. 
Table 1. CIRRUS Growth Data

\begin{tabular}{||c|c||}
\hline Time & $\begin{array}{c}\text { Number of } \\
\text { Locations }\end{array}$ \\
\hline $12 / 84$ & 3913 \\
$06 / 85$ & 5827 \\
$09 / 85$ & 6549 \\
$12 / 85$ & 6777 \\
$02 / 86$ & 8383 \\
$07 / 86$ & 8959 \\
$02 / 87$ & 11337 \\
$05 / 87$ & 13425 \\
$09 / 87$ & 14178 \\
$01 / 88$ & 15411 \\
$05 / 88$ & 16636 \\
$10 / 88$ & 18241 \\
$02 / 89$ & 19782 \\
$06 / 89$ & 20470 \\
$09 / 89$ & 21911 \\
$02 / 90$ & 23622 \\
$05 / 90$ & 24140 \\
$12 / 90$ & 28842 \\
$12 / 91$ & 33871 \\
$09 / 92$ & 39068 \\
\hline
\end{tabular}


Table 2. PLUS Growth Data

\begin{tabular}{||c|c||}
\hline Time & $\begin{array}{c}\text { Number of } \\
\text { Locations }\end{array}$ \\
\hline $11 / 84$ & 3499 \\
$05 / 85$ & 4320 \\
$11 / 85$ & 5111 \\
$05 / 86$ & 6141 \\
$11 / 86$ & 7227 \\
$05 / 87$ & 8253 \\
$11 / 87$ & 12046 \\
$05 / 88$ & 13176 \\
$10 / 88$ & 16015 \\
$05 / 89$ & 18642 \\
$05 / 90$ & 21643 \\
$12 / 90$ & 24823 \\
$12 / 91$ & 29294 \\
$09 / 92$ & 35152 \\
\hline
\end{tabular}


Table 3. The Gompertz Curve Fit-CIRRUS Full Data Set

\begin{tabular}{||c|c|c|c||}
\hline Parameter & Estimate & t-ratio & 2-tail sig. \\
\hline$B_{0}$ & 115960 & 4.578 & .0001 \\
\hline$B_{1}$ & .042794 & 5.669 & .0001 \\
\hline$B_{2}$ & .98893 & 697.867 & .0001 \\
\hline $\mathrm{R}^{2}=.9943$ & & & \\
\hline
\end{tabular}

Table 4. The Gompertz Curve Fit-PLUS Full Data Set

\begin{tabular}{||c|c|c|c||}
\hline Parameter & Estimate & t-ratio & 2-tail sig. \\
\hline$\beta_{0}$ & 96483 & 3.863 & .0001 \\
\hline$\beta_{1}$ & .024857 & 6.154 & .0001 \\
\hline$B_{2}$ & .92560 & 81.048 & .0001 \\
\hline $\mathrm{R}^{2}=.9940$ & & & \\
\hline
\end{tabular}

Table 5. The Gompertz Curve Fit-CIRRUS Revised Data Set

\begin{tabular}{||c|c|c|c||}
\hline Parameter & Estimate & t-ratio & 2-tail sig. \\
\hline$B_{0}$ & 39967 & 12.888 & .0001 \\
\hline$B_{1}$ & .10285 & 18.223 & .0001 \\
\hline$B_{2}$ & .97739 & 537.910 & .0001 \\
\hline $\mathrm{R}^{2}=.9969$ & & & \\
\hline
\end{tabular}


Table 6. The Gompertz Curve Fit-PLUS Revised Data Set

\begin{tabular}{||c|c|c|c||}
\hline Parameter & Estimate & t-ratio & 2-tail sig. \\
\hline$B_{0}$ & 66423 & 2.052 & .04 \\
\hline$B_{1}$ & .031999 & 2.932 & .003 \\
\hline$B_{2}$ & .90878 & 35.451 & .0001 \\
\hline $\mathrm{R}^{2}=.9845$ & & & \\
\hline
\end{tabular}

Table 7. The Logistic Curve Fit-CIRRUS Revised Data Set

\begin{tabular}{||c|c|c|c||}
\hline Parameter & Estimate & t-ratio & 2-tail sig. \\
\hline$B_{0}$ & .00003327 & 22.629 & .0001 \\
\hline$B_{1}$ & .0001908 & 21.476 & .0001 \\
\hline$B_{2}$ & .9538712 & 396.798 & .0001 \\
\hline $\mathrm{R}^{2}=.9959$ & & & \\
\hline
\end{tabular}

Table 8. The Logistic Curve Fit-PLUS Revised Data Set

\begin{tabular}{||c|c|c|c||}
\hline Parameter & Estimate & t-ratio & 2-tail sig. \\
\hline$B_{0}$ & .00003128 & 7.457 & .0001 \\
\hline$B_{1}$ & .0003966 & 7.601 & .0001 \\
\hline$B_{2}$ & .7569780 & 33.950 & .0001 \\
\hline $\mathrm{R}^{2}=.9887$ & & & \\
\hline
\end{tabular}


Figure 1. CIRRUS Growth Time Line

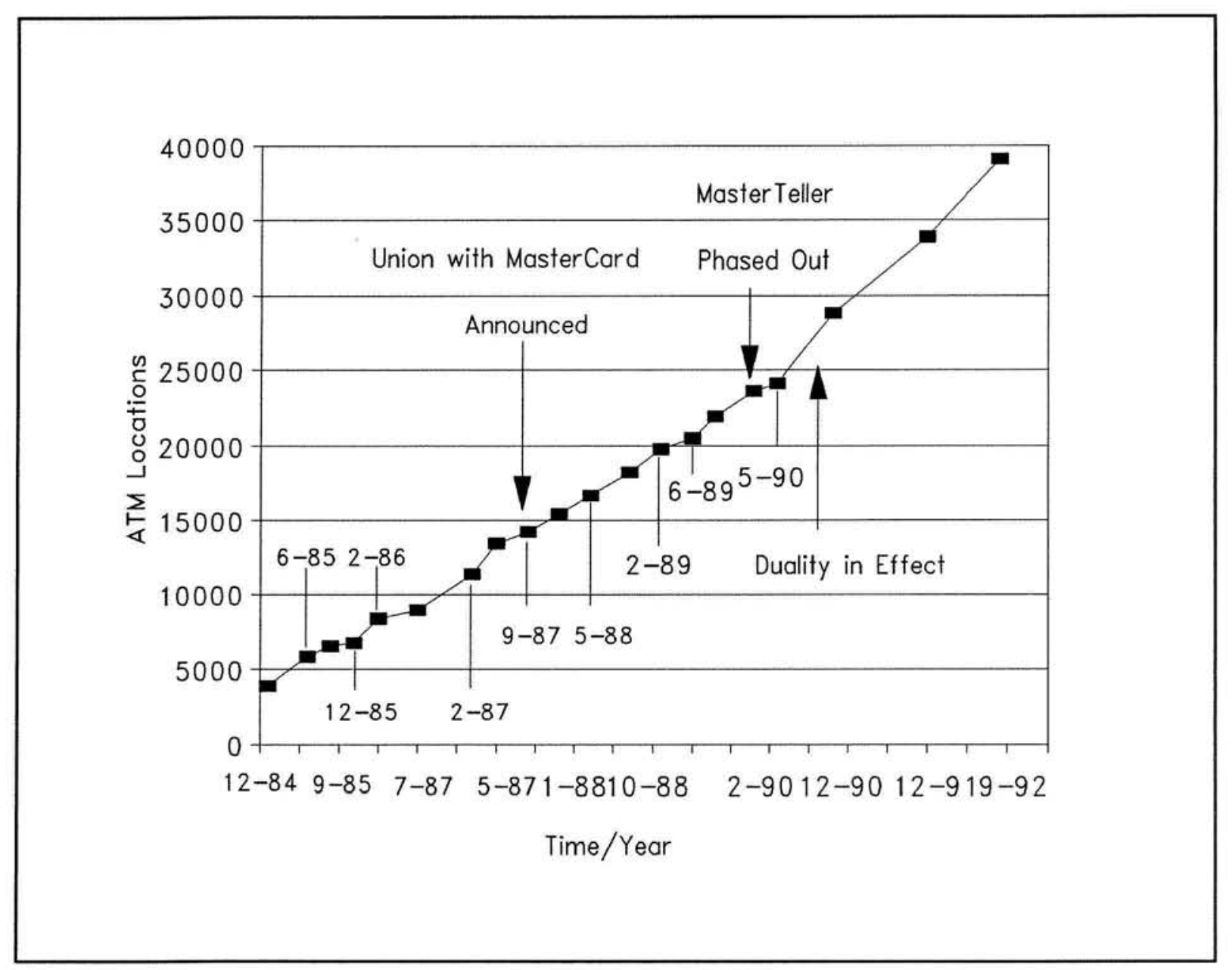


Figure 2. PLUS Growth Time Line

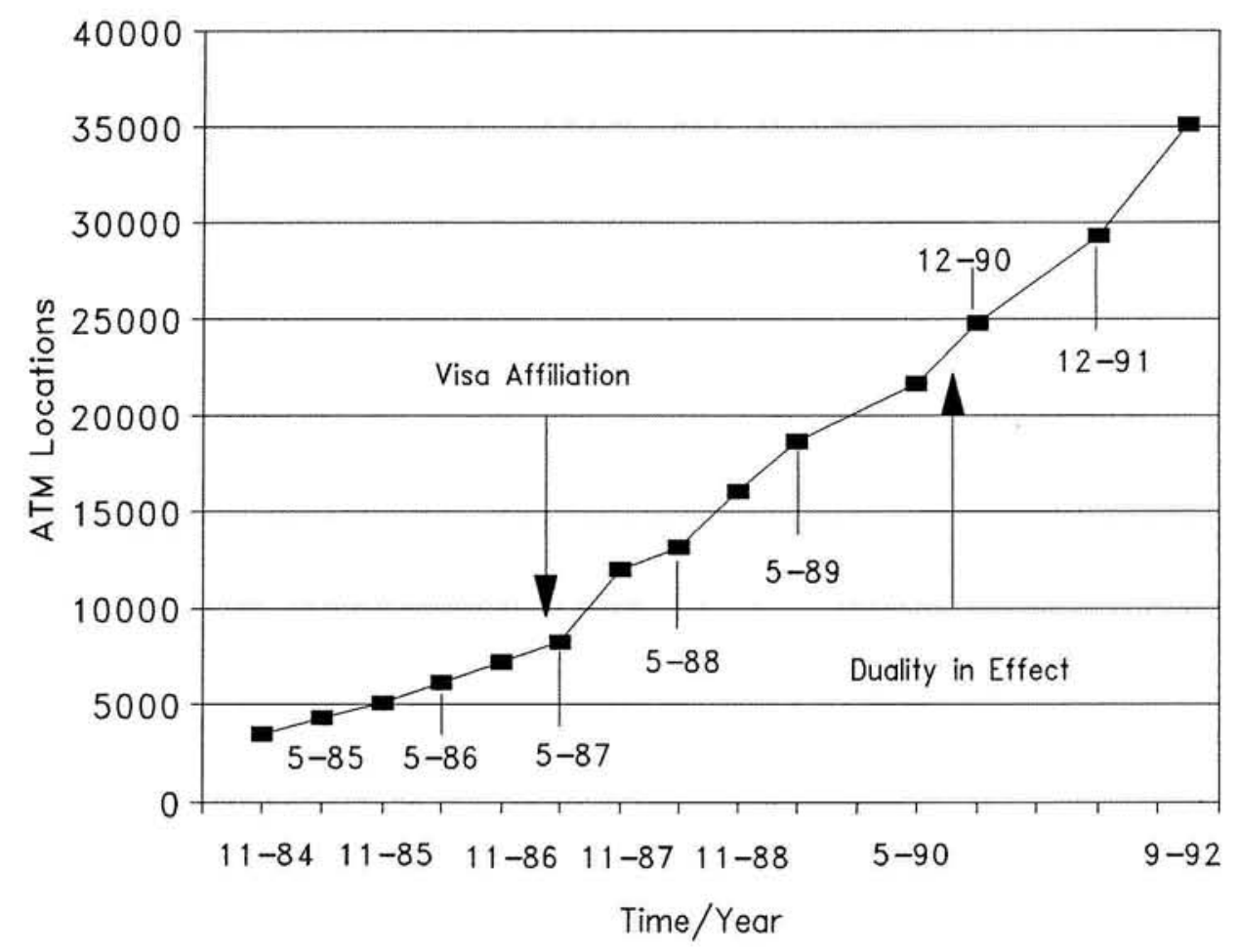


Figure 3. The Gompertz Curve, Full CIRRUS Data Set

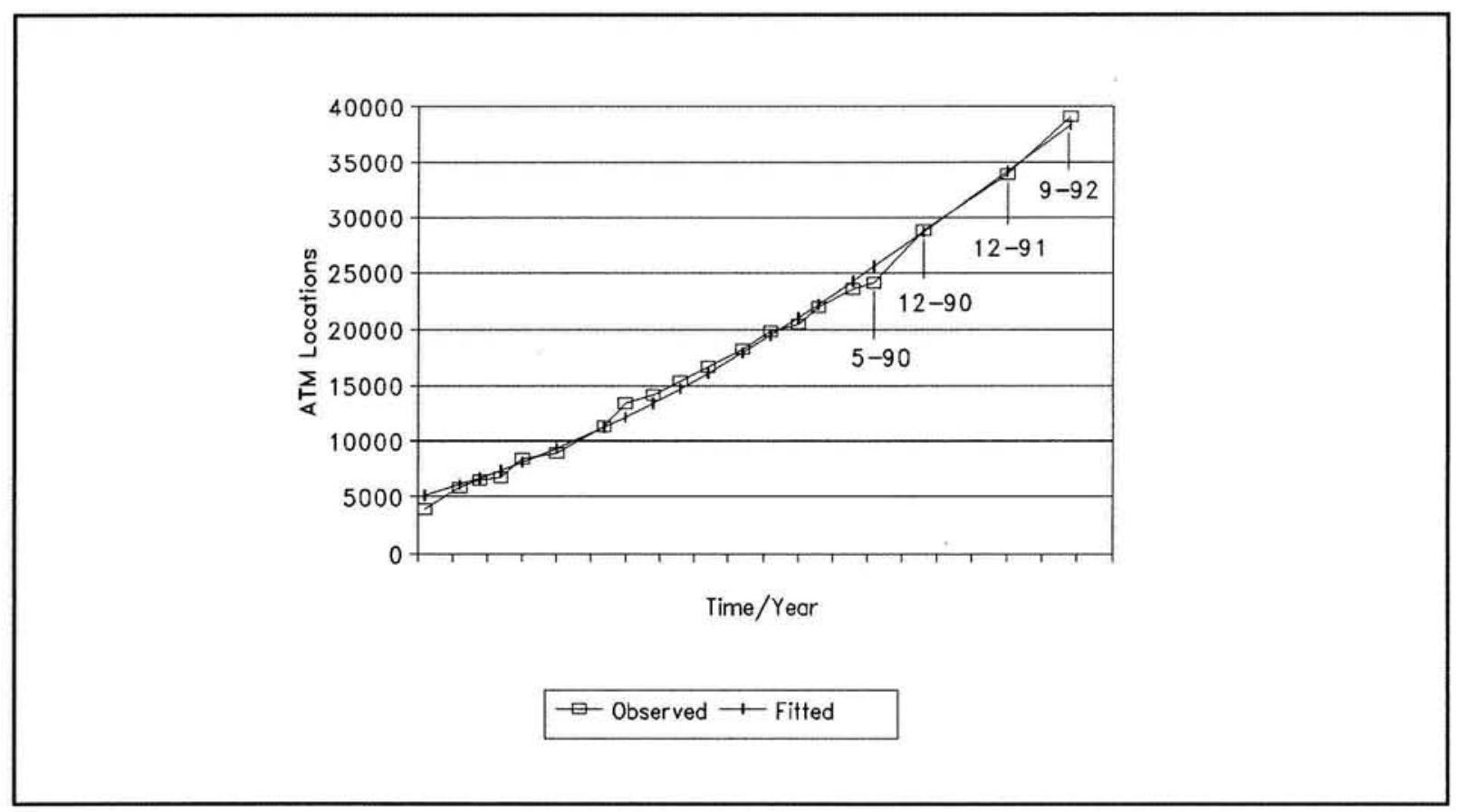

Figure 4. The Gompertz Curve, Full PLUS Data Set

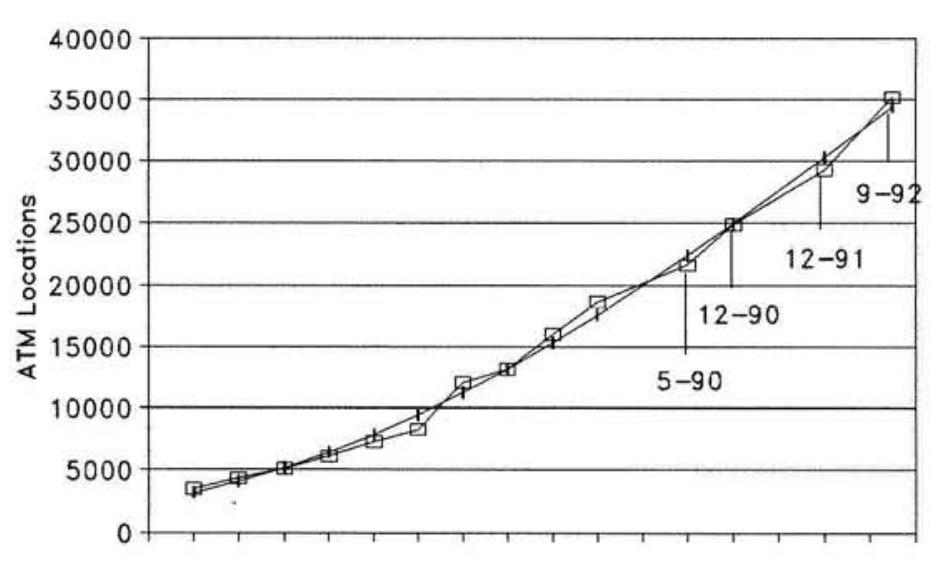

Time/Yeor

- Observed $\rightarrow$ Fitted 
Figure 5. The Gompertz Curve, Revised CIRRUS Data Set

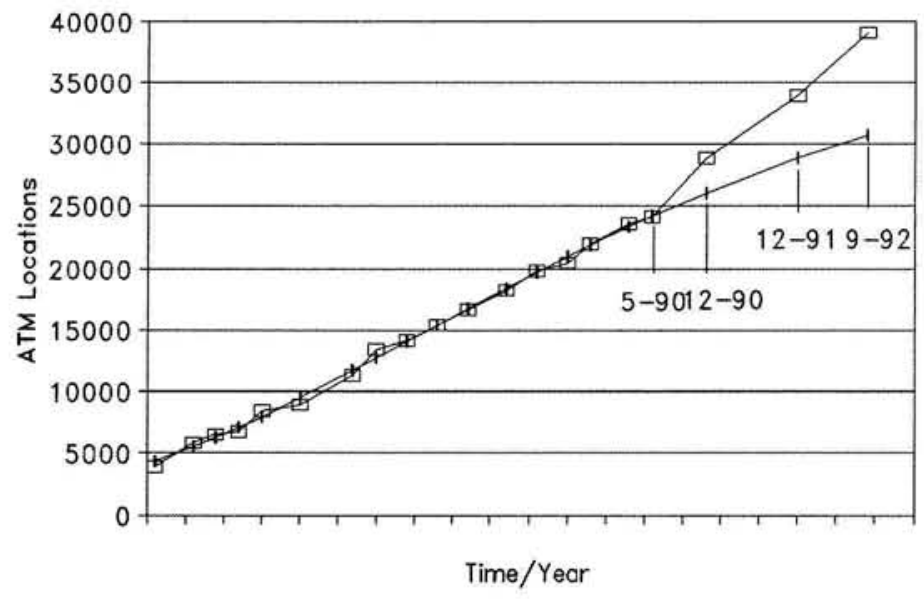

$\square$ Actual $\rightarrow$ Fitted

Figure 6. The Gompertz curve, revised PLUS data set

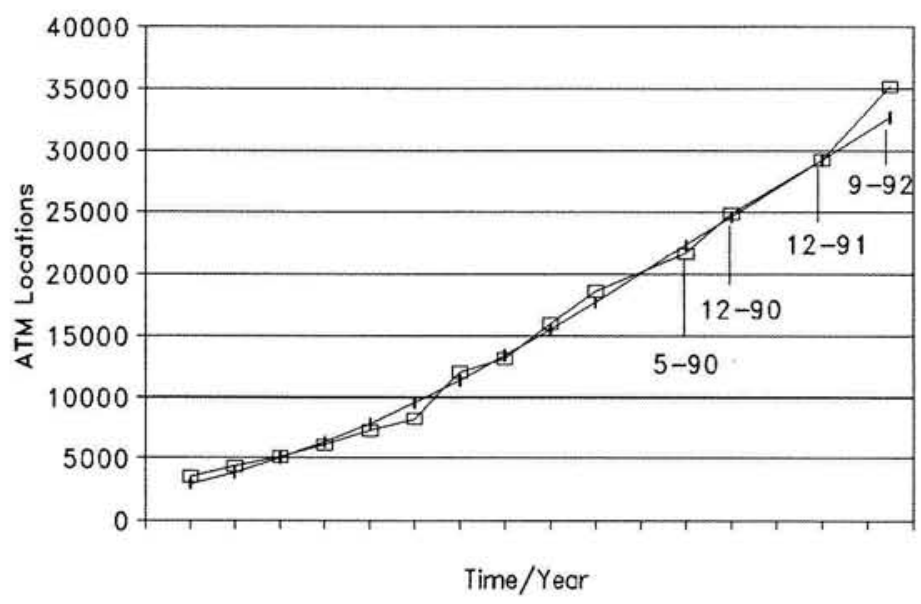

$\square$ Actual $\rightarrow$ Fitted 
Figure 7. The Logistic Curve, Revised CIRRUS Data Set

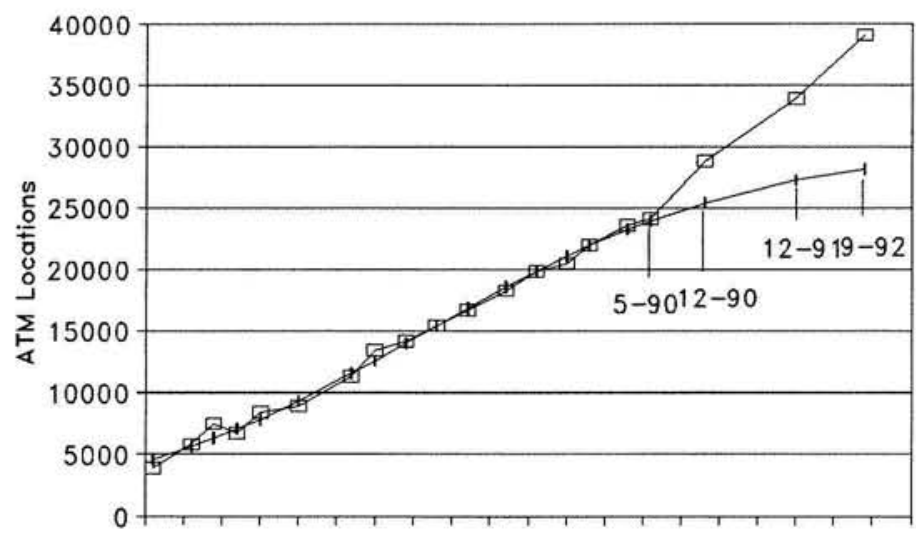

Time/Year

$\square$ Actual $\longrightarrow$ Fitted

Figure 8. The logistic curve, revised PLUS data set

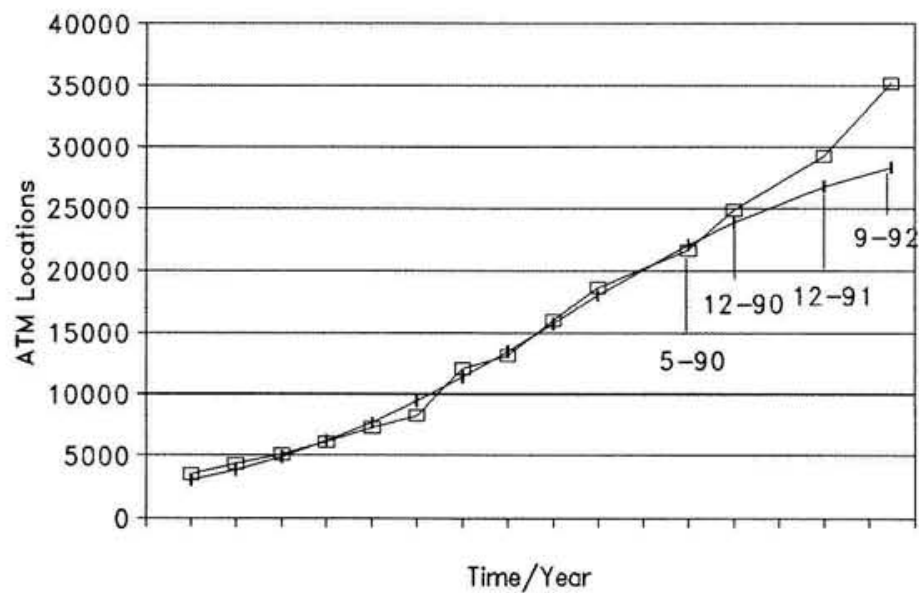

$\square$ Actual $\longrightarrow$ Predicted 